\title{
How much salt do adults consume in climate vulnerable coastal Bangladesh?
}

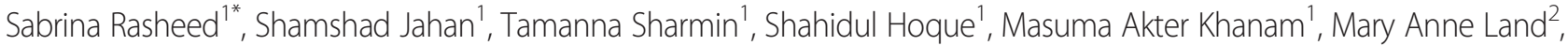 \\ Mohammad lqbal', Syed Manzoor Ahmed Hanifi', Fatema Khatun', Abul Kasem Siddique ${ }^{1}$ and Abbas Bhuiya ${ }^{1}$
}

\begin{abstract}
Background: Evidence from numerous studies suggests that salt intake is an important determinant of elevated blood pressure. Robust data about salt consumption among adults in Bangladesh is sparse. However, much evidence suggests saline intrusion due to sea level rise as a result of climate change exposes more than 20 million people to adverse effects of salinity through the food and water supply. The objective of our study was to assess salt consumption among adults in a coastal region of Bangladesh.
\end{abstract}

Methods: Our study was cross sectional and conducted during October-November 2011. A single 24 hour urine was collected from 400 randomly selected individuals over 18 years of age from Chakaria, a rural, coastal area in Southeastern Bangladesh. Logistic regression was conducted to identify the determinants of high salt consumption.

Results: The mean urinary sodium excretion was $115 \mathrm{mmol} / \mathrm{d}(6.8 \mathrm{~g}$ salt). Based on logistic regression using two different cutoff points (IOM and WHO), housewives and those living in the coastal area had a significantly higher probability of high salt intake compared with people who were engaged in labour-intensive occupations and who lived in hilly areas.

Conclusion: It is important to create awareness about the implication of excessive salt intake on health and to develop strategies for reducing salt intake that can be implemented at the community-level. A sustainable policy for salt reduction in the Bangladeshi diet should be formulated with special emphasis on coastal areas.

Keywords: 24 h urinary excretion, Salt consumption, Coastal area, Climate change, Bangladesh

\section{Background}

Hypertension is a major risk factor for cardiovascular diseases which now account for more than $27 \%$ of all deaths in Bangladesh [1]. The amount of dietary salt consumed is an important determinant of blood pressure levels and a modest reduction in salt has been found to have a significant and, from a population perspective, important effect on lowering blood pressure [2-5]. It has been estimated that decreasing population-level salt intake from the estimated global levels of 9-12 g/d [6] to the recommended level of $5 \mathrm{~g} / \mathrm{d}$ [7] would result in significant reduction of blood pressure and would reduce the world wide stroke rate and cardiovascular disease rate by $23 \%$ and $17 \%$, respectively $[8,9]$. Achieving this reduction would

\footnotetext{
* Correspondence: sabrina1@icddrb.org

'icddr,b, 68 Shaheed Tajuddin Ahmed Sarani, Mohakhali, Dhaka 1212, Bangladesh

Full list of author information is available at the end of the article
}

project to prevent 2.5 million deaths worldwide each year $[8,9]$. While sodium is essential to sustain human life, the recommended daily consumption for meeting physiological need is only $1.5 \mathrm{~g}$ (3.8 g salt) [10]. The WHO recommendation of $5 \mathrm{~g}$ salt/d reflects a pragmatic compromise between the beneficial and achievable in terms of reducing salt consumption [7].

No current definitive estimate of population salt consumption in Bangladesh exists. Of two reported studies, one involves pregnant women in the southeastern coastal area and showed urinary sodium excretion of $170 \mathrm{mmol} /$ day (equivalent $9 \mathrm{~g}$ salt) [11]. The other study was of 10 expatriate Bangladeshi patients with renal disease living in East London and showed that the two daily major meals combined to contain $10 \mathrm{~g}$ of salt per day [12]. The latter study is useful for understanding that a lot of salt is added to the Bangladeshi meal. 
The low lying coastal belt of Bangladesh is highly vulnerable to the effects of climate change. Sea levels are rising, storms and cyclones are occurring more frequently, and soil and water salinity are increasing [13]. It is estimated that 20 million people living in coastal Bangladesh are already facing increased exposure to diseases like hypertension by the increased salinity of the water supply $[14,15]$. In coastal areas it is estimated that salt intake from drinking water can range from 1.2-16 g/day depending on the water source and the season [15]. Therefore, it is important that levels of salt consumption among adults in coastal areas are established and factors associated with high salt consumption are investigated.

\section{Method}

\section{Study area}

The study was conducted in Chakaria -a rural area of the Southeastern coastal region of Bangladesh - in October and November 2011. Locally produced raw salt is ubiquitous, widely used and inexpensive in Chakaria. Because of the area's propensity for seasonal flooding and extensive shrimp cultivation, saline intrusion in the cultivable land has had a negative impact on local agriculture and livestock in some communities. Details of the study area are reported elsewhere [16]. For our study 3 unions (Bangladesh's smallest administrative unit) were selected to represent geographic variation (plains, hilly and coastal). Village residents above 18 years of age were randomly selected for a 24 hour urine collection, anthropometric measurements and administration of a survey.

\section{Study subjects}

Random sampling was carried out by selecting individuals from the existing Health and Demographic Surveillance System (HDSS), Chakaria. The list provided names and addresses of 3,581 adults over 18 years of age from 5 villages of 3 Unions representing geographical variations present in the area. The villages of the plains were large; therefore, two villages from coastal and hilly areas were randomly chosen to obtain a population pool similar to that of the single selected plains village.

To calculate the required sample size for the study we used the following formula:

$$
\mathrm{n}=\frac{\mathrm{t}^{2} \mathrm{xp}(1-\mathrm{p})}{\mathrm{m}^{2}}
$$

$\mathrm{n}=$ required sample size, $\mathrm{t}=$ confidence level at $95 \%$ (standard value of 1.96), $\mathrm{p}$ =estimated prevalence of people consuming $<5 \mathrm{~g}$ of salt/day (0.5), $\mathrm{m}=$ margin of error at $5 \%$ (standard value of 0.05 ) [17]. With the assumption that $50 \%$ of people will be consuming over $5 \mathrm{~g}$ of salt per day and a participation rate of $95 \%$ we invited 403 individuals to participate. From the list of 3,581 we invited every 3rd individual to participate in the study. If the selected person was not available the next person on the list was approached (Figure 1). Among those who were available 15 were excluded. A few people refused to participate $(n=6)$. Urine samples of 9 people were discarded due to suspected incomplete collection as determined by communication with the participant and urinary volumes $<250 \mathrm{ml}$. Complete data from 388 individuals were available for analysis. All selected participants were living independently in their own homes and reported no known illness.

All subjects provided written consent to participate. The study received ethical clearance from International Centre for Diarrheal Disease Research, Bangladesh (ICDDR, B).

\section{Recording of health variables}

The weight of each subject was measured using a digital electric balance (Seca alpha, $\mathrm{GmBH}$ \& Company, Range 0.1-150 kg); height was measured using a locally constructed scale. For both measurements the subject was instructed to be barefoot and to remove any heavy clothing. Body Mass Index was calculated from body weight and height measurements.

Three blood pressure measurement were taken from the right arm of the seated participant following a $5 \mathrm{mi}$ nute rest period using OMRON HEM-90XL automated

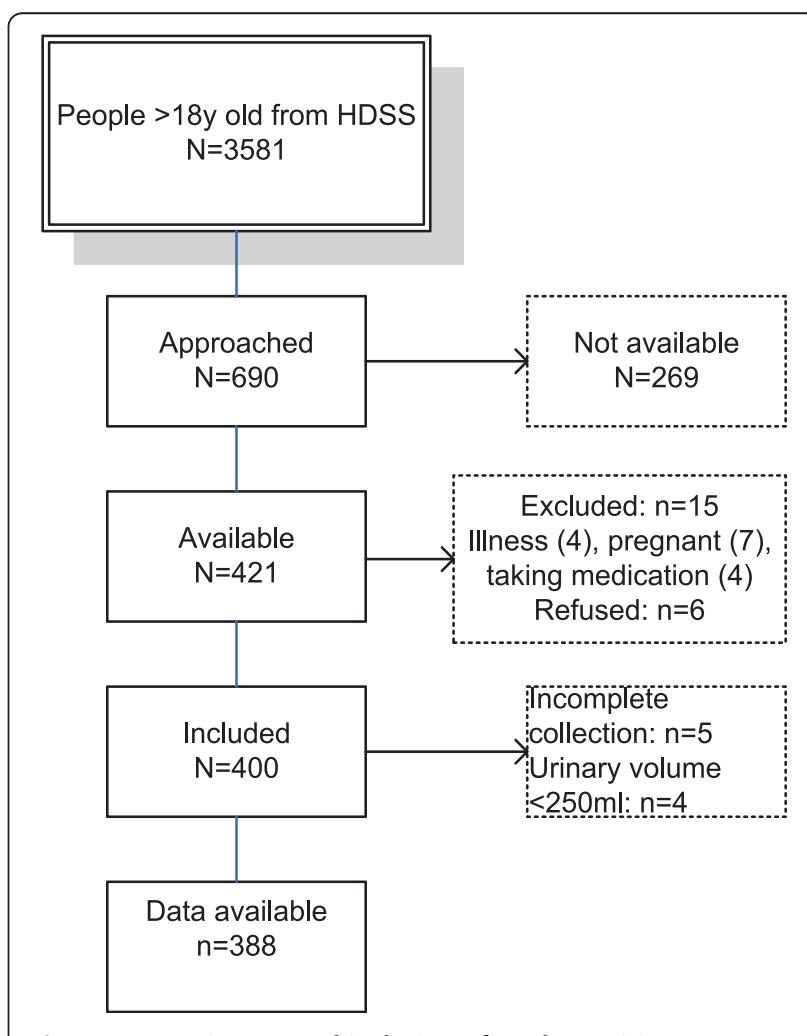

Figure 1 Recruitment and inclusion of study participants. 
sphygmomanometer which is a valid method used in clinical settings. The first measurement was discarded and the mean of the second and third measurements was used in the analysis. All readings were taken by a trained data collector with at least a bachelors' degree. Data collectors received a 2-day training on collecting anthropometric and blood pressure measurements. The training continued until measurements of the data collectors were $\pm 10 \%$ of the trainer. No measurement of inter-observer reliability was conducted in the study. In-field quality control was done through duplicate data collection for $10 \%$ of the respondents by field supervisors.

\section{4 hour urine collection}

The measurement of 24 hour urinary sodium excretion is considered the preferred method for determining population sodium intake [18]. The advantage of using this method is that it is not affected by bias related to self-reporting. However, it does not take into account electrolyte loss other than via kidney (such as sweat) and tends to underestimate true intake by $10-15 \%$ [18].

For our study 24 hour urine was collected in a clean plastic container which was given to the subjects along with detailed verbal instructions. A smaller plastic container and a bag were also provided so that people could collect the urine if they had to go outside of the house for short times during the 24 hour urine collection period. During collection of the urine sample questions were asked to determine the start and end time of the collection period and completeness of collection. The container was brought to the Chakaria field office where the urine volume was measured and $10 \mathrm{ml}$ of each sample were preserved at $-4^{\circ} \mathrm{C}$ for analysis. The $10 \mathrm{ml} \mathrm{sam}$ ples were transported to Dhaka for laboratory analysis to determine sodium and potassium levels in the urine.

To guard against under collection, urine samples were rejected if urinary volume was $<250 \mathrm{ml}$. The individual sodium excretion values were the product of sodium concentration in the urine and urinary volume corrected to 24 hour and expressed in $\mathrm{mmol} / \mathrm{d}$. A factor of 22.99 was used to convert mmol to $\mathrm{mg}$ of sodium. For the conversion from g sodium to sodium chloride, a factor of 2.54 was used [19].

\section{Socioeconomic variables}

The asset quintile was calculated based on ownership of 14 assets (almirah, table/chair, van/rickshaw, choki/khat or bed, radio, television, bicycle, motorcycle, fridge, sofa, electric fan, sewing machine, telephone and electricity) collected from the HDSS data. Principal component analysis was conducted for calculating weights of the asset index scores [20]. The scores were divided into 3 tertiles with the lowest tertile representing the poorest households and the highest tertile representing the richest. Data on age, education and occupation of selected individuals was also collected from the HDSS.

\section{Statistical analysis}

Means, standard deviations and ranges of all the variables were calculated and normality of the data was checked. The proportion of people with high salt consumption was calculated using the cut off points $(1.5 \mathrm{~g}$ of sodium) proposed by the Institute of Medicine (IOM) and $(1.96 \mathrm{~g}$ of sodium or $5 \mathrm{~g}$ of salt) the WHO $[10,18]$. For univariate analysis, a Chi square test was used to the find difference between proportions. Two different logistic regression models were run using the 2 different cut off points as we were interested in the correlates of high salt intake in the population. The independent variables in the model included age, sex, occupation, education, household wealth index and geographic location of the subject's residence. First, logistic regression with stepwise function was used to come up with 2 parsimonious models where all the variables significantly related to the outcome variable at the $10 \%$ level were included. Finally, variables that were included in both models (one with the IOM cut off, the other with the WHO cut off) were used to create the final models. A simple logistic regression was run to estimate the regression coefficients. All data were analyzed using SPSS version 17.

\section{Results}

The mean daily sodium excretion of the population was $115 \mathrm{mmol}$ (equivalent $6.7 \mathrm{~g}$ of salt) per day. The mean total urinary volume was 1.5 litres (SD 0.79). The distribution of salt excretion was skewed towards the right with $59.6 \%$ of the population having a daily intake higher than the WHO recommendation (5 g of salt/day); 75\% had a daily intake higher than the IOM recommendation (1.5 g of sodium/day) (Figure 2).

The mean age of the study participants was 44.6 years, with the range 25-105 years. The sample had a similar proportion of males and females. The majority of females were housewives whereas males were mainly in engaged in labour-intensive occupations. The population was distributed among hilly, coastal and plains which represented the geographical variation of the study area (Table 1). In bivariate analysis using both cut offs (IOM and $\mathrm{WHO}$ ), area of residence was associated with high salt consumption with people in the coastal region consuming more than those living in other areas. Occupation was also associated with high salt consumption: housewives consumed significantly more than people in other occupations. When using the WHO cutoff, results showed that females consumed significantly more salt than males (Table 1). 


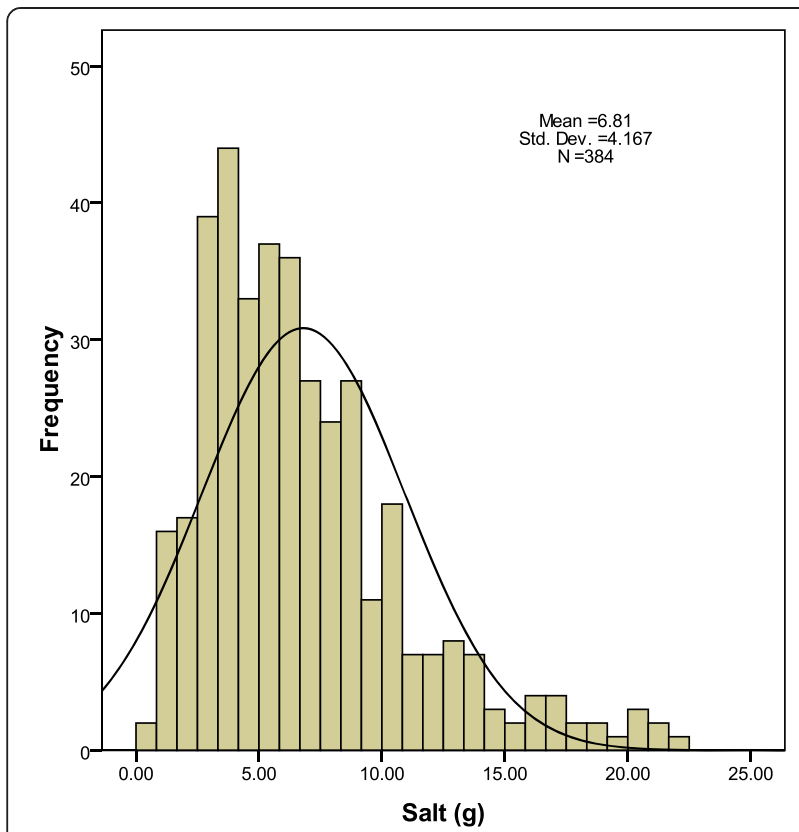

Figure 2 Distribution of salt excretion in gram/day.

According to logistic regression, using the IOM cut off compared to those who lived in hilly areas the odds of high salt consumption were 1.7 times higher among people living in the plains and 3.3 times higher among those living in the coastal area. Compared to people in labour-intensive occupations the odds of high salt consumption were 1.9 times higher among housewives (Table 2). The model using the WHO cut off of $5 \mathrm{~g}$ /day yielded similar results (Table 2).

\section{Discussion}

Our study is the first to describe the level and correlates of salt consumption among adults in coastal Bangladesh. The mean salt consumption of this population was $6.7 \mathrm{~g} / \mathrm{d}$ (or $115 \mathrm{mmol} \mathrm{Na} / \mathrm{d}$ ) is comparable to those reported in Australia [21], Finland [22], Ghana and West Africa [23] and lower than those reported in other developed countries [24] and in South East Asian countries [6]. Also, the level of salt consumption was less than that reported in a study of pregnant women in the coastal belt of Bangladesh [15]. However, $75 \%$ of the study population still consumed more than their biological need and $59 \%$ of the population consumed more than the WHO recommended $5 \mathrm{~g} / \mathrm{d}$ of salt. Having this much of the population exceeding the recommended levels of salt consumption is very concerning given the alarming levels of hypertension present in Bangladeshi adults [25]. Although results from the study area may not be representative of the nation, it is applicable to the coastal area of Bangladesh where 20 million people live
Table 1 Characteristics of the study population by proportion consuming more salt than amount recommended by IOM and WHO

\begin{tabular}{|c|c|c|c|c|}
\hline Characteristics & $\mathrm{N}$ & $\%$ & $\begin{array}{l}\text { Proportion (\%) } \\
\text { consuming }>1.5 \mathrm{~g} \\
\text { sodium/d (IOM) }\end{array}$ & $\begin{array}{l}\text { Proportion }(\%) \\
\text { consuming }>1.96 \mathrm{~g} \\
\text { sodium } / \mathrm{d}(\mathrm{WHO})\end{array}$ \\
\hline \multicolumn{5}{|l|}{ Age (y): } \\
\hline $25-39$ & 171 & 44 & 77.6 & 65.5 \\
\hline $40+$ & 217 & 56 & 72.8 & 57.1 \\
\hline \multicolumn{5}{|l|}{ Sex: } \\
\hline Male & 198 & 51 & 72.2 & $56.1^{*}$ \\
\hline Female & 190 & 49 & 77.8 & 66.1 \\
\hline \multicolumn{5}{|l|}{ Occupation: } \\
\hline Labour & 74 & 36 & 72.1 & $56.4^{* *}$ \\
\hline Non-labour & 140 & 19 & 70.3 & 50.0 \\
\hline Housewives & 174 & 45 & 78.7 & 69.0 \\
\hline \multicolumn{5}{|l|}{ Education: } \\
\hline 0 years & 143 & 37 & 74.8 & 60.8 \\
\hline $1-5$ years & 198 & 51 & 73.2 & 59.1 \\
\hline $5+$ years & 47 & 12 & 80.9 & 68.1 \\
\hline \multicolumn{5}{|c|}{ Body Mass index: $\left(\mathrm{kg} / \mathrm{m}^{2}\right)$} \\
\hline $\begin{array}{l}\text { Underweight } \\
(<18.5)\end{array}$ & 93 & 24 & 68.8 & 55.9 \\
\hline $\begin{array}{l}\text { Normal weight } \\
(18.5-24.9)\end{array}$ & 235 & 61 & 75.3 & 60.9 \\
\hline Overweight ( $\geq 25)$ & 56 & 15 & 80.4 & 67.9 \\
\hline \multicolumn{5}{|l|}{ Blood pressure: ${ }^{t}$} \\
\hline Normotensive & 353 & 91 & 75.1 & 61.6 \\
\hline Hypertensive & 34 & 9 & 70.6 & 52.9 \\
\hline \multicolumn{5}{|c|}{ Geographical distribution: } \\
\hline Coastal area & 155 & 40 & $83.2^{* *}$ & $70.3^{* *}$ \\
\hline Hilly area & 111 & 29 & 64.0 & 50.5 \\
\hline Plains area & 122 & 31 & 73.8 & 58.2 \\
\hline \multicolumn{5}{|l|}{ Wealth Index: } \\
\hline Lowest & 106 & 33 & 80.2 & 65.1 \\
\hline Middle & 107 & 34 & 71.0 & 57.9 \\
\hline Highest & 106 & 33 & 72.6 & 56.6 \\
\hline $\begin{array}{l}\text { Urinary volume (I) } \\
\text { Mean(SD) }\end{array}$ & \multicolumn{4}{|c|}{$1.5( \pm 0.79)$} \\
\hline $\begin{array}{l}\text { Urinary Salt (g) } \\
\text { Mean(SD) }\end{array}$ & \multicolumn{4}{|c|}{$6.8( \pm 4.16)$} \\
\hline
\end{tabular}

${ }^{* *} \mathrm{p}<0.01,{ }^{*} \mathrm{p}<0.05,{ }^{+}$Normotensive: Systolic $<140 \mathrm{Hg} \mathrm{mm}$ and diastolic $<90$ $\mathrm{Hg} \mathrm{mm}$.

Hypertensive: Systolic $\geq 140 \mathrm{Hg} \mathrm{mm}$ or diastolic $\geq 90 \mathrm{Hg} \mathrm{mm}$.

[14] and are likely to be exposed to high levels of environmental salinity due to climate change.

Area of residence was by far the strongest predictor of high salt consumption in our study with those in the 
Table 2 Correlates of high salt intake based on both IOM (>1.5 g sodium/d) and WHO (>1.96 g sodium/d) recommendations

\begin{tabular}{|c|c|c|c|c|c|}
\hline Variables & & Odds ratio (IOM) & $95 \% \mathrm{Cl}$ & Odds ratio (WHO) & $95 \% \mathrm{Cl}$ \\
\hline \multirow[t]{3}{*}{ Occupation } & Labour & $\operatorname{Ref}^{*}$ & & $\operatorname{Ref}^{f * *}$ & \\
\hline & Non-labour & 0.95 & $0.50-1.80$ & 0.80 & $0.44-1.43$ \\
\hline & Housewife & 1.90 & $1.09-3.30$ & 2.21 & $1.35-3.63$ \\
\hline \multirow[t]{3}{*}{ Geographical area } & Hilly & $\operatorname{Ref}^{* *}$ & & $\operatorname{Ref}^{* * *}$ & \\
\hline & Plains & 1.74 & $0.98-3.11$ & 1.62 & $0.95-2.79$ \\
\hline & Coastal & 3.31 & $1.81-6.06$ & 3.06 & $1.78-5.28$ \\
\hline
\end{tabular}

${ }^{*} p<0.05,{ }^{* *} p<0.001$.

coastal area consuming the most. This is the first study to indicate that even with areas in close proximity, living directly in coastal areas makes a difference in salt consumption. Globally there is a rising concern that climate change will critically affect the freshwater resources of the world [26]. In Bangladesh, a country bearing some of the worst effects of global climate change, the rivers and ground water in coastal area are threatened by increased salinity from the Bay of Bengal [15]. The coastal population relies heavily on rivers, ground water and ponds for washing, bathing, and drinking water which could result in increased exposure to sodium [27]. Saline intrusion in the groundwater could also affect the sodium content of foods produced, and, therefore, cause increased consumption of salt without people being aware that their intake is increasing. Researchers have reported that excess salinity can be toxic to plants leading to reduced plant yield and plant death [28]. Depending on the variety of plants, sodium can accumulate within different parts of the plant despite existence of good mechanism of excluding sodium within the plant system [28]. It is important to investigate both these indirect sources of salt consumption and the effects of increased salinity on the available food supply.

In our study housewives had significantly higher salt intake than people (males) in labour-intensive occupations. As the majority of the women we studied were housewives, we found that women tended to have higher salt intake then men. The average salt intake of females $(7 \mathrm{~g})$ is slightly less than those reported among pregnant women in one coastal location of Bangladesh [15]. However, in studies around the world researchers have shown that women tend to consume less salt than men $[6,29]$. Researchers have explained that the higher salt consumption among men was due to higher food intake. The explanation for the sex difference in salt consumption in our study may well lie in the context. In our study the men were engaged in labour-intensive occupations whereas women were mostly housewives. As $24 \mathrm{~h}$ urinary excretion takes no account of electrolyte loss other than through the kidneys [18], it is possible that the salt intake of men engaged in labour-intensive activities in Bangladesh's tropical climate may have been underestimated. Another caveat to the explanation could be that housewives had better access to discretionary salt during meal times and, therefore, consumed more. To understand the sex differential in salt consumption it may be important to give further consideration to the context in which salt is consumed.

There have been reports of a growing prevalence of hypertension in Bangladesh [30-32], a trend predicted to continue in coming years. According to a recent Bangladeshi national survey (2011), 19.4\% of males and 31.9\% of females above 35 years of age were hypertensive [33]. To complicate the scenario, saline intrusions due sea-level rise and other effects of climate change have put 20 million people in the coastal belt at health risk from environmental exposure to sodium [14,34]. Many researchers have shown that reduction of population-level salt intake is a cost-effective public health strategy $[35,36]$. However, despite the cost-effectiveness, only a few countries have made progress implementing such a public health strategy [36]. For Bangladesh, in the absence of national data on salt consumption, and with existing geographic variations in salt consumption, it is important to understand the different sources of dietary salt and the beliefs and practices around salt use for designing appropriate strategies for different communities. In view of the deleterious health consequences of high salt intake, special attention should be given to coastal areas prone to saline intrusion in food and water sources and areas where cheap raw salt is easily available [34,37]. So far the literature on climate change and health points to the proliferation of infectious disease (diarrhea), vector born disease (malaria) and diseases and health conditions due to migration and loss of livelihood [13]. However, direct health impacts of increased environmental salinity have yet to be addressed adequately. In view of the rising impact of climate change and the large number of people who will be affected, the link between increased salinity and health warrants attention.

\section{Strengths and limitations}

24 hour urine collection was used to estimate salt intake. This is considered the preferred method for the estimation 
of salt intake but it is not without limitations. One, 24 hour sodium collection may underestimate sodium excretion due to sodium being lost in sweat; and, two, there is no true method to determine under and over collection. We did however determine completeness of the urine samples both by asking each participant and by measuring urine volume. Other methods such as levels of creatinine and PABA to validate urine collection have been used in research elsewhere but were not used in this study. Some studies also used 24 hour dietary recalls to validate urinary sodium. In our study population salt is added to food mostly during preparation and packaged or pre-prepared foods were not eaten that frequently. As there is no published report for nutrient content of mixed Bangladeshi foods we decided not to conduct dietary recall.

The sample size was small and the method of participant selection meant that our participants were those who were available at the time of the home visit; this could have biased the sample. The level of salt consumption reported in the study does not represent the national levels.

\section{Conclusions}

Although the levels of salt consumption in the study population are lower than in some countries, more than three-fourths of the study population consumed more than biologically needed, and half consumed greater than the $5 \mathrm{~g}$ of salt daily. As salt consumption is a risk factor for hypertension, it is important that major sources of salt consumption are identified. Interventions to raise awareness about the detrimental health effects of excessive salt use should be designed for coastal communities. Looking to the future, policies that help to reduce salt consumption should be formulated for Bangladesh with special attention to climate-change-vulnerable coastal populations.

\section{Competing interests}

The authors report no conflict of interests.

\section{Authors' contribution}

SR analyzed the data and drafted the paper; SR, MI, TS, SJ, MAK, SMAH, SH designed and implemented the study and provided intellectual input into the analysis; SMAH, MAL, AKS, FK provided technical expertise, input in interpreting the results; and $A B$ provided overall supervision for design, analysis and drafting of the manuscript. All authors read and approved the final manuscript.

\section{Acknowledgements}

This study was funded by UnitedHealth group through Oxford Health Alliance Vision 2020 of Johns Hopkins University. icddr,b acknowledges with gratitude the commitment of UnitedHealth group to its research efforts. We would like to acknowledge Drs. Bruce Neal and Tracey Kohlmoos for their comments and continued interest in the topic. We would like to acknowledge George B. Smith for carefully copy editing the paper.

\section{Author details}

${ }^{1}$ icddr,b, 68 Shaheed Tajuddin Ahmed Sarani, Mohakhali, Dhaka 1212, Bangladesh. ${ }^{2}$ The George Institute for Global Health, PO Box M201, Missenden Rd., Camperdown, NSW 2050, Australia.
Received: 23 February 2014 Accepted: 4 June 2014

Published: 11 June 2014

\section{References}

1. World Health Organization: NCD country profiles, 2011. http://www.who. int/nmh/publications/ncd_profiles2011/en/.

2. Conlin PR: Eat your fruits and vegetables but hold the salt. Circulation 2007, 116(14):1530-1531.

3. Sacks FM, Svetkey LP, Vollmer WM, Appel LJ, Bray GA, Harsha D, Obarzanek E, Conlin PR, Miller ER 3rd, Simons-Morton DG, Karanja N, Lin PH, DASH-Sodium Collaborative Research Group: Effects on blood pressure of reduced dietary sodium and the Dietary Approaches to Stop Hypertension (DASH) diet. N Engl J Med 2001, 344(1):3-10.

4. Cutler JA, Follmann D, Allender PS: Randomized trials of sodium reduction: an overview. Am J Clin Nutr 1997, 65(2 Suppl):643S-651S.

5. He FJ, MacGregor GA: A comprehensive review on salt and health and current experience of worldwide salt reduction programmes. J Hum Hypertens 2009, 23(6):363-384.

6. Brown IJ, Tzoulaki I, Candeias V, Elliott P: Salt intakes around the world: implications for public health. Int J Epidemio/ 2009, 38(3):791-813.

7. World Health Organization: Expert meeting on population salt reduction strategies for the prevention and control of non communicable diseases in South-East Asia Region. New Delhi: World Health Organization; 2013.

8. Strazzullo P, D'Elia L, Kandala NB, Cappuccio FP: Salt intake, stroke, and cardiovascular disease: meta-analysis of prospective studies. BMJ 2009, 339:b4567.

9. He FJ, Li J, Macgregor GA: Effect of longer term modest salt reduction on blood pressure: Cochrane systematic review and meta-analysis of randomised trials. BMJ 2013, 346: 11325

10. Institute of Medicine: Panel on dietary reference intake for electrolyte and water. Washington: Institute of Medicine; 2004

11. Khan AE, Ireson A, Kovats S, Mojumder SK, Khusru A, Rahman A, Vineis P: Drinking Water Salinity and Maternal Health in Coastal Bangladesh: Implications of Climate Change. Environ Health Perspect 2011, 119(9):1328-1332

12. de Brito-Ashurst I, Perry L, Sanders TAB, Thomas JE, Yaqoob MM, Dobbie H: Dietary salt intake of Bangladeshi patients with kidney disease in East London: An exploratory case study. e-SPEN, the European e-J of Clinical Nutr and Metab 2009, 4(1):e35-e40.

13. Contribution of Working Group II to the Fourth Assessment Report of the Intergovernmental Panel on Climate Change: Contribution of Working Group II to the Fourth Assessment Report of the Intergovernmental Panel on Climate Change: Climate Change 2007: Impacts, Adaptation and Vulnerability. Edited by Parry ML, Canziani OF, Palutikof JP, van der Linden PJ, Hanson CE. Cambridge: Cambridge University Press; 2007:976.

14. CEGIS: Impact of sea-level rise on land use, suitability and adaptation options: Coastal land zoning in the Southwest. Dhaka, Bangladesh: Centre for Environmental and Geographic Information Services; 2006.

15. Khan AE, Ireson A, Kovats S, Mojumder SK, Khusru A, Rahman A, Vineis P. Drinking water salinity and maternal health in coastal Bangladesh: Implication of climate change. Environ Health Perspective 2011, 119(9):1328-1332.

16. Hanifi MA, Mamun AA, Paul A, Hasan SA, Hoque S, Sharmin S, Urni F, Khan IR, Mahmood SS, Rasheed S, lqbal M, Moula A, Rahman M, Bhuiya A: Profile: the Chakaria Health and Demographic Surveillance System. Int J Epidemiology 2012, 41(3):667-675.

17. Food and Agriculture Organization: Conducting small-scale nutrition surveys: a field Manual, Nutrition Planning, Assessment and Evaluation Service, Food Policy and Nutrition Division, Food and Agriculture Organization. 1990:1-187.

18. World Health Organization: Reducing salt intake in populations: Report of a WHO Forum and Technical Meeting. Paris, France: World Health Organization; 2006.

19. Ribič CHZJ, Vertnik L, Vegnuti M, Cappuccio FP: Salt intake of the Slovene population assessed by $24 \mathrm{~h}$ urinary sodium excretion. Public Health Nutr 2010, 13(11):1803-1809.

20. Filmer D, Pritchett LH: Estimating wealth effects without expenditure data-or tears: an application to educational enrollments in states of India. Demography 2001, 38(1):115-132.

21. Charlton K, Yeatman H, Houweling F, Guenon S: Urinary sodium excretion, dietary sources of sodium intake and knowledge and practices around 
salt use in a group of healthy Australian women. Aust N Z J Public Health 2010, 34(4):356-363.

22. Laatikainen T, Pietinen P, Valsta L, Sundvall J, Reinivuo H, Tuomilehto J: Sodium in the Finnish diet: 20-year trends in urinary sodium excretion among the adult population. Eur J Clin Nutr 2006, 60(8):965-970.

23. Kaufman JS, Owoaje EE, James SA, Rotimi CN, Cooper RS: Determinants of hypertension in West Africa: contribution of anthropometric and dietary factors to urban-rural and socioeconomic gradients. Am J Epidemiol 1996, 143(12):1203-1218.

24. Cappuccio FP, Kerry SM, Micah FB, Plange-Rhule J, Eastwood JB: A community programme to reduce salt intake and blood pressure in Ghana [ISRCTN88789643]. BMC Public Health 2006, 6:13.

25. World Health Organization: The World Health Report 2002: Reducing Risks, Promoting Healthy Life. Geneva, Switzerland: World Health Organization; 2002.

26. Ebi KL, Sussman FG, Wilbanks TJ: Analyses of the effects of global change on human health and welfare and human systems. A Report by the U.S. Climate Change Science Program and the Subcommittee on Global Change Research. Edited by Gamble JL. Washington DC, U.S: Environmental Protection Agency; 2008.

27. Rahman AA, Ravenscroft $P$ : Ground water resources and development in Bangladesh. 2nd edition. Dhaka: The University Press Limited; 2003.

28. Munns R, James RA, Läuchli A: Approaches to increasing the salt tolerance of wheat and other cereals. J Exp Bot 2006, 57(5):1025-1043.

29. Ortega RM, Lopez-Sobaler AM, Ballesteros JM, Perez-Farinos N, RodriguezRodriguez E, Aparicio A, Perea JM, Andres P: Estimation of salt intake by $24 \mathrm{~h}$ urinary sodium excretion in a representative sample of Spanish adults. Br J Nutr 2011, 105(5):787-794.

30. Ahsan Karar Z, Alam N, Kim Streatfield P: Epidemiological transition in rural Bangladesh, 1986-2006. Global Health Action 2009, 1-9.

31. Sayeed MA, Banu A, Haq JA, Khanam PA, Mahtab H, Azad Khan AK: Prevalence of hypertension in Bangladesh: effect of socioeconomic risk factor on difference between rural and urban community. Bangladesh Med Res Counc Bull 2002, 28(1):7-18.

32. Saquib N, Saquib J, Ahmed T, Khanam MA, Cullen MR: Cardiovascular diseases and type 2 diabetes in Bangladesh: a systematic review and meta-analysis of studies between 1995 and 2010. BMC Public Health 2012, 12:434.

33. National Institute of Population Research and Training, Mitra and Associates, ICF International: Bangladesh Demographic and Health Survey 2011. Dhaka, Bangladesh and Calverton, Maryland, USA: NIPORT, Mitra and Associates, and ICF International; 2013

34. Khan A, Mojumder SK, Kovats S, Vineis P: Saline contamination of drinking water in Bangladesh. Lancet 2008, 371(9610):385.

35. Selmer RM, Kristiansen IS, Haglerod A, Graff-Iversen S, Larsen HK, Meyer HE, Bonaa $\mathrm{KH}$, Thelle DS: Cost and health consequences of reducing the population intake of salt. J Epidemiol Community Health 2000, 54(9):697-702.

36. Murray CJ, Lauer JA, Hutubessy RC, Niessen L, Tomijima N, Rodgers A, Lawes CM, Evans DB: Effectiveness and costs of interventions to lower systolic blood pressure and cholesterol: a global and regional analysis on reduction of cardiovascular-disease risk. Lancet 2003, 361(9359):717-725.

37. Rasheed S, Hanifi MA, lqbal M, Nazma N, Bhuiya A: Policy of universal salt iodization in Bangladesh: do coastal people benefit? J of Health, Population, and Nutri 2001, 19(2):66-72.

doi:10.1186/1471-2458-14-584

Cite this article as: Rasheed et al: How much salt do adults consume in climate vulnerable coastal Bangladesh? BMC Public Health 2014 14:584.

\section{Submit your next manuscript to BioMed Central and take full advantage of:}

- Convenient online submission

- Thorough peer review

- No space constraints or color figure charges

- Immediate publication on acceptance

- Inclusion in PubMed, CAS, Scopus and Google Scholar

- Research which is freely available for redistribution

Submit your manuscript at www.biomedcentral.com/submit 